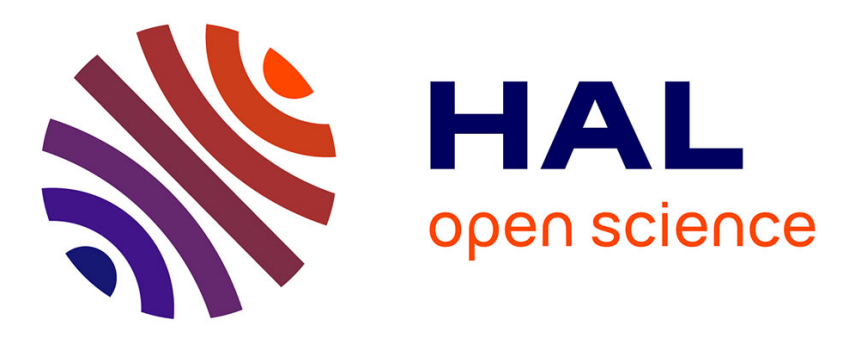

\title{
Investigation of the kinetics of MOCVD with a stagnation cell
}

\author{
O. Yu Gorbenko, W. Decker, G. Wahl
}

\section{To cite this version:}

O. Yu Gorbenko, W. Decker, G. Wahl. Investigation of the kinetics of MOCVD with a stagnation cell. Journal de Physique IV Proceedings, 1993, 03 (C3), pp.C3-25-C3-33. 10.1051/jp4:1993303 . jpa-00251360

\section{HAL Id: jpa-00251360 https://hal.science/jpa-00251360}

Submitted on 1 Jan 1993

HAL is a multi-disciplinary open access archive for the deposit and dissemination of scientific research documents, whether they are published or not. The documents may come from teaching and research institutions in France or abroad, or from public or private research centers.
L'archive ouverte pluridisciplinaire HAL, est destinée au dépôt et à la diffusion de documents scientifiques de niveau recherche, publiés ou non, émanant des établissements d'enseignement et de recherche français ou étrangers, des laboratoires publics ou privés. 


\title{
Investigation of the kinetics of MOCVD with a stagnation cell
}

\author{
O. YU GORBENKO, W. DECKER ${ }^{*}$ and G. WAHL ${ }^{*}$
}

\author{
Dept. of Chemistry, Moscow State University, B-234, 119899 Moscow, Russia \\ * Institut für Oberflächentechnik, Technische Universität Braunschweig, Bienroder Weg 53, \\ 38108 Braunschweig, Germany
}

\begin{abstract}
Solutions of the mass transfer equation in the stagnation cell are described. It is shown that the application of the stagnation cell can be used for the determination of $\mathrm{Da}^{\mathrm{s}}$, distinguishing different types of process control, sensoring gas phase condensation and homogeneous nucleation. The results obtained with cylindrical cell for MOCVD of YBCO are discussed.
\end{abstract}

\section{INTRODUCTION}

Many MOCVD processes occur in the diffusion controlled regime [1-3]. In a diluted gas mixture at the constant temperature the diffusion of reactants in the carrier gas can be described independently. The diffusion flux of each reactant $j_{s}$ is given by Fick equation:

$$
j_{s}=-D_{i, j} \nabla C_{i}
$$

where $D_{i j}$ - binary diffusion coefficient of $i$ in the mixture, $C_{i}-$ molar concentration of $i$.

The concentration gradient is determined by reactant concentration on the reacting surface $\left(\mathrm{C}_{\mathrm{is}}\right)$ and outside boundary layer $\left(\mathrm{C}_{\mathrm{io}}\right)$. For stagnation flow reactors [4] the formula

$$
j_{s}=D_{i j}\left(C_{i o}-C_{i s}\right) * S C^{1 / 3} R e^{1 / 2} / D
$$

is valid for the deposition rate on the surface, where Sc - Schmidt number, Re - Reynolds number, D diameter of flow inlet.

$\mathrm{C}_{\mathrm{is}}$ can be calculated from thermodynamical data. The deposition rate correlates with the shift of the chemical equilibrium. The chemical processes in the gas phase namely species transformation (elimination, association and dissociation, disproportion, etc.) (a), lead to formation of condensed phase (homogeneous nucleation) (b) lead to a variation of $\mathrm{D}_{\mathrm{ij}}$. Appearance of (b) is possible at high supersaturation $\mathrm{C}_{\mathrm{i}} / \mathrm{C}_{\mathrm{ie}}\left(\mathrm{C}_{\mathrm{ie}}\right.$ - equilibrum value of the component $\left.\mathrm{i}\right)$.

There is a lack of kinetic data for processes such as deposition of metal oxides (high $T_{c}$ superconductors, ferroelectric perovskites, magnetic spinels and garnets, solid ionics, glasses) using metal organic compounds (MOC). Today the complete kinetic description is impossible in difference to the CVD of Si [5-6]. The deposition in a stagnation cell is helpful to determine kinetic data for the deposition of oxides. 


\section{STAGNATION CELL}

A stagnation cell (fig. $1 \mathrm{a} \mathrm{b}$ ) can be arranged in a stagnation flow reactor (fig. $1 \mathrm{c}$ ). For the considerations in this section we assume, that no homogeneous reactions exist, the reactions at the surface are very fast and at the surface the concentration $C_{i s}=0$ of the precursor molecule $i$ is assumed. For the estimation we assume as a first approximation that in the cell are no convection effects. Then the deposition profile can be calculated by solution of the Laplace equation $\Delta C_{i}=0$, if the concentration $C_{i}$ of the component $i$ at $z=L$ is known. The solution of the equation is independent of $D_{i j}$. For an infinite rectangular split (fig. 1a) with width $d$ and depth $L$ with the boundary condition on the wall $C_{i s}=0$ and at the inlet of the cell $\mathrm{C}_{\mathrm{i}}(\mathrm{x}, \mathrm{L})=\mathrm{C}_{0}$ the solution [7] is

$$
C_{i}(x, z)=\frac{4 C_{0}}{\pi} \sum_{I=1}^{\infty} \frac{1}{(2 I-1)} \frac{e^{\frac{\pi(2 I-1) z}{d}}-e^{-\frac{\pi(2 I-1) z}{d}}}{e^{\frac{\pi(2 I-1) L}{d}}-e^{-\frac{\pi(2 I-1) L}{d}}} \sin \frac{\pi(2 I-1) x}{d}
$$

According (1) (minus sign is omitted below) in the case $L » d$ we have after substitution $z^{\prime}=L-z$ :

$$
j_{s}\left(z^{\prime}\right)=\frac{4 D_{i j} C_{o}}{d} \frac{e^{\frac{\pi z^{\prime}}{d}}}{\left(e^{\frac{2 \pi z^{\prime}}{d}}-1\right)}
$$

and for large $z^{\prime}\left(2 \pi z^{\prime} / d>1\right)$ :

$$
j_{s}\left(z^{\prime}\right) \rightarrow \frac{4 D_{i j} C_{0}}{d} * e^{-\frac{\pi z^{\prime}}{d}}
$$

For a cylindrical cell (radius $R$ and depth $L$, fig. $1 b$ ) with boundary conditions $C_{i s}=0$ and $C(r, L)=C_{0}$ the solution has the form

$$
C_{i}(r, z)=2 C_{0} \sum_{n=1}^{\infty} \frac{1}{B_{n} J_{1}\left(B_{n}\right)} \frac{e^{\frac{B_{n} z}{R}}-e^{-\frac{B_{n} z}{R}}}{e^{\frac{B_{n} I}{R}}-e^{-\frac{B_{n} I}{R}}} J_{0}\left(\frac{B_{n} I}{R}\right)
$$

where $J_{0}, J_{1}$ are the Bessel functions of 0 and 1 st order, $B_{n}$ - zeros of $J_{0}\left(J_{0}\left(B_{n}\right)=0\right)$.

For $L$ » $R$ after substitution $z^{\prime}=L-z$ and using $B_{n}-B_{n-1} \approx \pi$ it can be derived:

$$
j_{s}\left(z^{\prime}\right) \approx \frac{2 D_{i j} C_{o}}{R} \frac{e^{\frac{\left(\pi-B_{1}\right) z^{\prime}}{R}}}{\left(e^{\frac{\pi z^{\prime}}{R}}-1\right)}
$$

and for large $z^{\prime}\left(2 \pi z^{6} / R>1\right)$ :

$$
j_{s}\left(z^{\prime}\right) \rightarrow \frac{2 D_{i j} C_{o}}{R} e^{-\frac{B_{0} z^{\prime}}{R}}
$$

So for the deposition controlled by gas phase diffusion with $\left(\mathrm{C}_{\mathrm{is}}=0\right)$ the following conclusions can be made: 1 . Geometry of the cell determines the normalized deposition profile; 2 . The stoichiometry of the deposit is independent of $z$ ' if different elements are deposited from different precursors.

With the boundary conditions used the deposition rate is infinite at $z^{\prime}=0$ as $C_{i}$ changes unsteady from $\mathrm{C}_{0}$ to 0 . A more realistic condition $\mathrm{C}_{\mathrm{i}}(\mathrm{r}, \mathrm{L})$ is desirable. Using Fourier-Bessel expansion and neglecting negative exponents we obtain: 


$$
j_{s}\left(z^{\prime}\right)=\frac{D_{i j}}{R} \sum_{n=1}^{\infty} B_{n} A_{n} e^{-\frac{B_{n} z^{\prime}}{R}}
$$

The $A_{n}$ are determined by $C_{i}(r, L)$ :

$$
A_{n}=\frac{2}{J_{1}^{2}\left(B_{n}\right) R^{2}} \int_{0}^{R} r C_{i}(r, L) J_{0}\left(\frac{B_{n} r}{R}\right) d r
$$

For $C_{i}(r, L)=C_{0}$ eq. (9) leads to (7). As $C_{i}(r, L)>0$ the sum of members with $n>1$ can be neglected in comparison with the first member for large $\mathrm{z}^{6}$ :

$$
j_{s}\left(z^{\prime}\right) \rightarrow \frac{B_{1} D_{i j}}{R} A_{1} e^{-\frac{B_{1} X}{R}}
$$

The formula (11) gives the same normalized deposition profile for component $i$ as formula (8). The profile is valid at $z^{\prime} \geq 0$ for the boundary condition

$$
C_{i}(r, L)=C_{0} J_{0}\left(\frac{B_{1} r}{R}\right)
$$

with deposition rate

$$
j_{S}\left(z^{\prime}\right)=\frac{D_{i j} B_{1} J_{1}\left(B_{1}\right)}{R} e^{-\frac{B_{1} z^{\prime}}{\bar{R}}}
$$

The profile is referred to so-called ground diffusion mode (GM).

In order to determine the applicability of equ. 13 the Laplace equation was solved numerically with the code FLUENT V3.03. For these simulations the more realistic case was assumed, that above the stagnation surface $(\mathrm{z}=\mathrm{L})$ a stagnant boundary layer with the thickness $\delta$ was formed. The thickness $\delta$ was varied between 0 and $10 \mathrm{~mm}$. For the simulations an uniform grid with a step width of $0.2 \mathrm{~mm}$ was used. With growth of $z$ ' the normalized concentration profile of $i$ in radial direction converges to $J_{0}\left(B_{1} r / R\right)$. Inlet $C_{i}$ profile with growth of $\delta$ converges rapidly to a function different from $J_{0}\left(B_{1} r / R\right)$.

The comparison of the normalized profiles which were calculated numerically with the profile calculated by equ.(13) shows that at $z^{6}>z_{0}^{*}$ the profile can be described by equ.(13) with a maximum deviation of $5 \%$. The value of $z_{0}^{6}$ is: $z_{0}^{c}=0.25 \mathrm{~d}$ and $z_{0}^{*}=0.5 \mathrm{R}$. The normalization of the profiles were carried out with a value at $\mathrm{z}^{6}>\mathrm{z}_{0}^{\circ}$. At these calculations $\mathrm{d}$ and $\mathrm{R}$ were varied between $2<\mathrm{d}<7 \mathrm{~mm}$ and $1<\mathrm{R}<4 \mathrm{~mm}$. The depth was always $\mathrm{L}=20 \mathrm{~mm}$.

In order to observe flow effects we carried out calculations for a stagnation flow reactor (fig.1c) at different $R e$. Inlet velocity profile was $v=v_{m}\left(1-4 r^{2} D^{-2}\right), D=10 \mathrm{~mm}, R=3.6 \mathrm{~mm}$. At low $\operatorname{Re}(\operatorname{Re}<40, \operatorname{Re}$ was calculated with the mean velocity $v_{m} / 2$ and $D$ ) the normalized inlet $C_{i}$ and $j_{s}$ profiles coincide with profiles obtained with the stagnant boundary layer. For high $R e$ the convection leads to enrichment of $i$ in the cell. With growth of $z$ ' the influence of convection decreases. For $\operatorname{Re}=75$ the convection only is important for $z^{6}<1 \mathrm{~mm}$. For larger $z^{6}$ the profile converges to the GM profile.

Summarizing the basic features are:

1. For $z^{\prime}>z^{\prime}$ the deposition profile corresponds to the GM profile in the normalized form. The plot of $\ln j_{s}\left(z^{\prime}\right)$ vs. $z^{\prime}$ is a straight line.

2. For $\mathrm{z}_{1}^{6}<\mathrm{z}^{\prime}<\mathrm{z}_{0}{ }_{0}\left(\mathrm{z}_{1}^{6} \approx 0.06 \mathrm{R}\right.$ or $\left.0.05 \mathrm{~d}\right)$ the following profiles were determined empirically (deviation from simulated profile less than $6 \%$ for $R$ in the range $1-3.6 \mathrm{~mm}, \mathrm{~d}$ in the range $1.4-5.2 \mathrm{~mm}$ ): 


$$
\begin{aligned}
& j_{s}\left(d, z^{\prime}\right) \sim \frac{e^{\frac{2 \pi z^{\prime}}{d}}}{\left(e^{\frac{3 \pi z^{\prime}}{d}}-3 / 4\right)} \\
& j_{s}\left(R, z^{\prime}\right) \sim \frac{e^{\frac{3}{2} \frac{\left(\pi-B_{1}\right) z^{\prime}}{d}}}{\left(e^{\frac{3}{2} \frac{\pi z^{\prime}}{d}}-6 / 7\right)}
\end{aligned}
$$

3. For $\operatorname{Re}>50$ the deposition profile at the entrance is steeper and it can be described by an equation of the type of equ.(7).

These calculations are only correct for $\mathrm{Kn}<0.01$ where $\mathrm{Kn}$ is the Knudsen number determined as the ratio of the mean free length $\lambda$ in the gas mixture to cell width. In the gas mixture Ar-MOC (collision radius $10 \AA$ ) at $T=1073 \mathrm{~K}$ and $\mathrm{p}=10$ mbar we have found that the calculations are correct at $\mathrm{R}>\sim 0.5 \mathrm{~mm}$.

\section{INFLUENCE OF GAS PHASE KINETICS}

The basic elementary gas phase reactions involved in MOCVD are:

I. $\mathrm{A} \rightarrow \mathrm{B}+(\Sigma \mathrm{P})$

II-1. $A+R \rightarrow B+(\Sigma P)$

II-2. $\mathrm{A}+\mathrm{A} \rightarrow \mathrm{B}+(\Sigma \mathrm{P})$

II-3. $\mathrm{A}+\mathrm{B} \rightarrow \mathrm{C}+(\Sigma \mathrm{P})$

where $A, B, C$ - metal containing species, $R$ - gas phase reactant containing no metal atoms, $\Sigma P$ elimination products.

In the case of reaction II-2 with the rate constant $\mathrm{k}$ we have the following equations of mass transfer in the stagnation cell:

$$
\begin{aligned}
& D_{A} \Delta C_{A}-2 k C_{A}^{2}=0 \\
& D_{B} \Delta C_{B}+k C_{A}^{2}=0
\end{aligned}
$$

We define the formal function $\mathrm{C}_{\mathrm{f}}$ :

$$
C_{f}=D_{A} C_{A}+2 D_{B} C_{B}
$$

Evidently

$$
\Delta C_{f}=0, j_{s}=D_{A} \frac{\partial C_{A}}{\partial n}+2 D_{B} \frac{\partial C_{B}}{\partial n}=\frac{\partial C_{f}}{\partial n}
$$

where $n$ is a direction parallel to $j_{s}$.

The equation for $C_{f}$ is a Laplace equation. If $C_{i s}=0$ ( $i$ is $A$ and/or $B$ ) then $C_{f s}=0$. Inlet boundary condition for $\mathrm{A}$ in the absence of reactions is $\mathrm{C}_{\mathrm{A}}=\mathrm{f}\left(\zeta_{1}, \zeta_{2}, \zeta_{3}\right)>0$ where $\zeta_{1}, \zeta_{2}, \zeta_{3}$ are orthogonal coordinates. 
In the presence of reaction for each point at the inlet we consider the conversion factor $\omega\left(\zeta_{1}, \zeta_{2}, \zeta_{3}\right)=2 C_{B} /\left(C_{A}+2 C_{B}\right)$ where $0 \leq \omega \leq 1$. So the boundary condition for $C_{f}$ is

$$
c_{f}\left(\xi_{1}, \xi_{2}, \xi_{3}\right)=\left(\omega\left(\xi_{1}, \xi_{2}, \xi_{3}\right) *\left(D_{B}-D_{A}\right)+D_{A}\right) * f\left(\xi_{1}, \xi_{2}, \xi_{3}\right)=\tau f
$$

If $\omega=$ const then $\mathrm{C}_{\mathrm{fs}}=$ const $* \mathrm{f} . \tau$ defined by $(20)$ has the dimension of a diffusion coefficient. It is equal to $D_{A}$ if reaction occurs only in the cell (cold wall reactor) or to $D_{B}$ if rapid reaction takes place outside. Otherwise $\tau$ is between $D_{A}$ and $D_{B}$ determined by the volume Damköhler number $\mathrm{Da}^{v}=$ $\mathrm{k}^{*} \mathrm{~L}^{*} \mathrm{C}_{0} / \mathrm{v}_{0}$, where $\mathrm{C}_{0}$ is inlet concentration of $\mathrm{A}$ and $\mathrm{L}$ a characteristic length. For reaction II-2 the inlet conversion factor depends on $\mathrm{C}_{\mathrm{i}}$. So the assumption $\omega=$ const is not valid. For the reaction $\mathrm{I}$ inlet conversion factor is independent $C_{0}$ (also $\mathrm{Da}^{v}=\mathrm{k}^{*} \mathrm{~L} / \mathrm{v}_{0}$ ). Reactions II-1 occur in MOCVD at the $\mathrm{C}_{\mathrm{R}} \gg \mathrm{C}_{\mathrm{A}}$. $C_{R}$ can be included in $k$ then mass transfer equations for $C_{A}$ and $C_{B}$ are the same as for reaction $I$. Reactions II-3 are absent in the case of MOCVD processes using a single precursor.

The molecular size determines the value of $D_{i j}$. So a remarkable change of $D_{i j}$ for metal carriers is observed in reactions II-2, II-3. A series of reactions II-2 (II-3) results in a decrease of diffusivity. The condensation of nuclei on the surface is an other mass transfer effect. The rate of condensation $I_{c}$ is determined from the binary collision theory:

$$
I_{C}=\pi \gamma n_{i} \overline{V_{i}} \sum_{N} r_{N}^{2} n_{N}, j_{S}=\gamma C_{i} \frac{\overline{V_{i}}}{4}, \overline{V_{i}}=\sqrt{\frac{8 R T}{\pi M_{i}}}
$$

where $\gamma$ is the accomodation coefficient, $C_{i}$ - concentration of $i$ in the gas phase, $n_{i}, n_{N}$ - numbers of $i$ and nuclei in volume unit, $M_{i}-$ molecular mass of $i, r_{N}$-radius of the nucleus.

The expression can be used for $r_{N}<\lambda$. Particles produced by the growth of nuclei in the gas phase during LPCVD obey this condition [8]. In the presence of homogeneous nucleation the deposition profile has a form between the profiles with minimum and maximum of $D_{i j}$.

For the evaluation of experimental profiles we recommend to calculate the ratio of normalized deposition profiles to the standard profile (Q). The standard profile is the profile calculated in section 1 . If $Q$ deviates strongly from $Q=1$ the initial hypothesis about the pure diffusion controlled deposition can not be used. If $Q \approx 1$ for large $z^{\prime}$ and $Q>1$ for small $z$ ' then condensation takes place. $Q$ is the lower limit of $D_{i j}$ variation for carriers of $i$. If $Q \approx 1$ for large $z^{\prime}$ and $Q<1$ for small $z^{\prime}$ the elimination reactions are present. Nevertheless this case seems to be hypothetical as conversion factor for reaction I doesn't depend on the concentration of reactant. If $Q \approx 1$ for all $z$ ' it means that the conversion factor is constant at the cell inlet. Increase (decrease) of absolute deposition rate on the walls of the cell with temperature growth indicates elimination (condensation) processes in the gas phase. No significant variation of deposition rate in the temperature range means conversion factor 0 or 1 at the cell inlet. The realibility of the technique is enhanced if simultaneous deposition of metal components occur.

\section{SURFACE KINETICS}

The kinetics of the first order reaction can be used as a boundary condition in the stagnation cell:

$$
D_{i j} \frac{\partial C_{i}}{\partial n_{s}}+k C_{i}=0
$$

where $\mathrm{n}_{\mathrm{s}}$ - direction normal to the deposition surface, $\mathrm{k}$ - reaction constant of the first order reaction.

The kinetic investigation in the cylindrical stagnation cells [9-15] were described. Solutions with boundary condition $(22)$ and $\mathrm{C}_{\mathrm{i}}(\mathrm{r}, \mathrm{L})=\mathrm{C}_{0}$ is 


$$
C_{i}(x, z)=2 C_{0} \sum_{n=1}^{\infty} \frac{J_{1}\left(\alpha_{n}\right)}{\alpha_{n}\left(J_{1}^{2}\left(\alpha_{n}\right)+J_{0}^{2}\left(\alpha_{n}\right)\right)} \frac{e^{\frac{\alpha_{n} z}{R}}+p_{n} e^{-\frac{\alpha_{n} z}{R}}}{e^{\frac{\alpha_{n} L}{R}}+p_{n} e^{-\frac{\alpha_{n} L}{R}}} J_{0}\left(\frac{\alpha_{n} Y}{R}\right)
$$

where $\alpha_{n}$ are solutions of equation $\mathrm{Da}^{s} \mathrm{~J}_{0}(\alpha)=\alpha \mathrm{J}_{1}(\alpha)$, $\mathrm{p}_{\mathrm{n}}$ is calculated by $\left(\alpha_{\mathrm{n}}-\mathrm{Da}^{s}\right) /\left(\alpha_{\mathrm{n}}+\mathrm{Da}^{s}\right)$ and $\mathrm{Da}^{s}$ is the surface Damköhler number $\left(\mathrm{Da}^{s}=\mathrm{kR} / \mathrm{D}_{\mathrm{ij}}\right)$. For small $\alpha_{1}$ the value of $\alpha_{1}$ is given by $\alpha_{1}=\left(2 \mathrm{Da}^{s}\right)^{1 / 2}[11,12]$.

For $\mathrm{Da}^{s}>1 \alpha_{\mathrm{n}}$ approximates $\mathrm{B}_{\mathrm{n}}$. For $\mathrm{Da}^{s}<1 \alpha_{\mathrm{n}}$ approximates $\mathrm{B} 1_{\mathrm{n}}$, where $\mathrm{B} 1_{\mathrm{n}}$ are zeros of $\mathrm{J}_{1}$ (generally $B_{n-1}<B 1_{n}<\alpha_{n}<B$ ). Condition $\alpha_{n} \rightarrow B 1_{n}$ means $J_{1}\left(\alpha_{1}\right) \rightarrow \alpha / 2$ and $J_{1}\left(\alpha_{n+1}\right) / \alpha_{n+1} \rightarrow 0$. So at $D a^{s} \rightarrow 0$ the reacting component is homogeneously distributed in the cell. The deposition rate is constant for all $\mathrm{z}$ and equal to $\mathrm{KC}_{0}$. The conditions with small $\mathrm{Da}^{\mathrm{s}}$ are of great practical importance as for industrial LPCVD in the horizontal reactor, CVI of porous substrates [14,15] and fibre bundle coatings [16].

The experimental data can be approximated by the first term of equ.(23)

$$
j_{S}(z) \sim e^{\frac{\alpha_{1}\left(L-z^{\prime}\right)}{R}}+p_{1} e^{-\frac{\alpha_{1}\left(L-z^{\prime}\right)}{R}}
$$

where $z$ is replaced by $z=L-z$ '.

The profile is a function of single parameter $\mathrm{Da}^{\mathrm{s}}$. Therfore $\mathrm{Da}^{\mathrm{s}}$ can be determined by the profile. In the case of large $\alpha_{1}$ the negative exponent in equ.(24) can be neglected:

$$
\ln \left(j_{s}\left(z^{\prime}\right)\right) \sim-\frac{\alpha_{1} z^{\prime}}{R}
$$

Simulations carried out with FLUENT 3.03 in the geometry of stagnation flow reactor (fig.1c) for $\mathrm{Da}^{s}=0.69$ and $\mathrm{Da}^{\mathrm{s}}=2.7 * 10^{-4}$ gave good accordance with the analytical calculations (fig. 2 , subscript sc is used for normalized profiles).

\section{EXPERIMENTAL}

The MOCVD of $\mathrm{YBa}_{2} \mathrm{Cu}_{3} \mathrm{O}_{7-\mathrm{x}}$ films was investigated using vapor of thd-complexes $(2,2,6,6$ tetramethylheptandion-3,5-ates) of $\mathrm{Y}, \mathrm{Ba}, \mathrm{Cu}$ and diglyme obtained by evaporation of aerosol. A hot wall stagnation flow reactor was used. Experimental details can be found in [17]. Process parameters: pressure $2000 \mathrm{~Pa}$, inlet temperature $270^{\circ} \mathrm{C}$, total flow $33 \mathrm{l} / \mathrm{h}$ including $30 \mathrm{l} / \mathrm{h} \mathrm{O}_{2}(\mathrm{STP})$. Analysis of deposits was fulfilled with EDX.

The influence of the deposition temperature on the profiles in the cylindrical cell (radius $2 \mathrm{~mm}$, length $20 \mathrm{~mm}$ ) was studied. The deposition profiles obtained at $650^{\circ} \mathrm{C}, 750^{\circ} \mathrm{C}$ and $850^{\circ} \mathrm{C}$ are shown in fig. 3. At $650^{\circ} \mathrm{C}$ deposition profiles for $\mathrm{Y}$ and $\mathrm{Cu}$ correlate with $\mathrm{GM}$ profile. Ba-profile at $650^{\circ} \mathrm{C}$ doesn't agree with the ground diffusion mode profile. The experimental data can be approximated by equ.(25) with $\alpha_{1}=1.2$ which corresponds to $\mathrm{Da}^{\mathrm{s}}=0.9$ (points with $\mathrm{z}^{\prime}<0.25 \mathrm{~mm}$ were not taken into account). The result can be compared with data for MOCVD of YBCO films [1] which show that process is diffusion controlled at app. $\mathrm{T}>600^{\circ} \mathrm{C}$ :

Growth of deposition temperature to $750^{\circ} \mathrm{C}$ results in change of deposition profiles for $\mathrm{Y}$ and $\mathrm{Cu}$. Deposition profile of $Y$ doesn't agree with the GM in the used range of $z$ ' (it was normalized to GM profile at the last experimental point available). Homogeneous nucleation in the gas phase is obvious because of the very small equilibrium vapor pressure of $\mathrm{Y}_{2} \mathrm{O}_{3}$ at $750^{\circ} \mathrm{C}$. Very small crystals of $\mathrm{Y}_{2} \mathrm{O}_{3}$ were observed in the YBCO films obtained by MOCVD [18,19]. In the case of $\mathrm{Cu} Q \geq 1$ was found and the profile converges to the GM profile in the z' range used. So condensation reactions can be assumed for 
Cu species under the conditions. Ba profile has $Q$ values in the range $Q \leq 1$.

At the of deposition temperature of $850^{\circ} \mathrm{C}$ new effects occur. For $\mathrm{Cu}$ nearly the GM profile is observed for $z^{\prime}>0.5 \mathrm{~mm}$. The change of the condensed phase $\left(\mathrm{CuO} \rightarrow \mathrm{Cu}_{2} \mathrm{O}\right)$ in the thermodynamic equlibrium can be the reason. It is interesting that the $\mathrm{P}_{\mathrm{O} 2}-\mathrm{T}$ conditions for the growth of epitaxial $\mathrm{YBCO}$ films correspond to the $\mathrm{CuO} / \mathrm{Cu}_{2} \mathrm{O}$ equilibrium [20]. $\mathrm{Y}$ shows the same behaviour as at $750^{\circ} \mathrm{C}$. The $\mathrm{Ba}$ profile converges to the diffusion controlled profile.

The results correlate with data on MOCVD of YBCO [1,18-20] and explain e.g. the $\mathrm{Y}_{2} \mathrm{O}_{3}$ inclusions in YBCO films.

\section{CONCLUSIONS}

Deposition in the stagnation cell can be used for the investigation of MOCVD with different processes, e.g. gas phase condensation and homogeneous nucleation processes. The technique enables determination of $\mathrm{Da}^{\mathrm{s}}$. The different deposition profiles of $\mathrm{Y}, \mathrm{Ba}$ and $\mathrm{Cu}$ shows, that it is difficult e.g. to deposit on carbon fibre bundles a coating with a composition independent of the position on the fibre.

\section{REFERENCES}

1. Wahl G. Jahrbuch von Oberflächentechnik 49 (1993) 253.

2. Blocher J.M. Thin Solid Films 77 (1981) 51.

3. Fitzer E. J.de Phys.IV Col.C2 suppl.J.de Phys.II 1 (1991) 509.

4. Chin D.T., Tsang C.H. J.Electrochem.Soc. 125 (1978) 1461.

5. Coltrin M.E., Kee R.J., Evans G.H. J.Electrochem.Soc. 136 (1989) 819.

6. Kleijn C.R. Transport Phenomena in Chemical Vapor Deposition Reactors, Delft (1991).

7. Bronstein I.N., Semendjajev K.A. Taschenbuch der Mathematik, 22. Aufl, (1984) 496.

8. Murthy T.U.M.S., Miyamoto M., Shimbo M., Nishizawa J.-J. J.Cryst. Growth 33 (1976) 1.

9. Wise H, Ablow C.N J.Chem.Phys. 29.(1958) 634; Wood B.J., Wise H. J.Chem.Phys. 29 (1958) 1416. 10. Armas B., Combescure C., Diaz-Salgado C. Proceed.V European Conf. on CVD Uppsala(Sweden) (1985) 183.

11. van den Brekel C.H.J, Fonville R.M.M., van der Straten P.J.M., Verspui G. Proceed. of VIII Int.Conf. on CVD (1981) 142.

12. van den Brekel C.H.J., Lersmacher B. Proceed. IV European Conf. on CVD, Eindhoven (The Netherlands) (1983) 321.

13. Egashira Y., Sorita T., Shiga S., Ikuta K., Komiyama H. J.de Phys. IV Col.C2 suppl.J.de Phys. II 1 (1991) 55.

14. Fitzer E., Fritz W., Schoch G. J.de Phys. IV Col.C2 suppl.J.de Phys.II 1 (1991) 143.

15. Naslain R., Langlais F., Fedou R. J.de Phys. 50 Col.C5 (1989) 191.

16. Stumm T., Fitzer E, Wahl G. J.de Phys. III 2 (1992) 1413.

17. Decker W., Nürnberg A., Pulver M., Stolle R., Wahl G., Erokhin Yu.Yu., Gorbenko O.Yu., Graboy I.E., Kaul A.R., Sommer M., Vogt U. Proceed. of Int. Conf. on CVD Honolulu (USA) (1993) to be published.

18. Schulte B., Maul M., Häusler P., Adrian H. Appl.Phys.Lett. 62 (1993) 633.

19. Lu P., Li Q., Zhao J., Chern C.S., Gallois B., Norris P., Kear B., Cosandey F. Appl.Phys.Lett. 60 (1992) 1265.

20. Yamane H., Hasei M., Kurosawa H., Watanabe K., Awaji S., Kobayashi, Hirai T., Muto Y. Physica C 190 (1991) 79. 


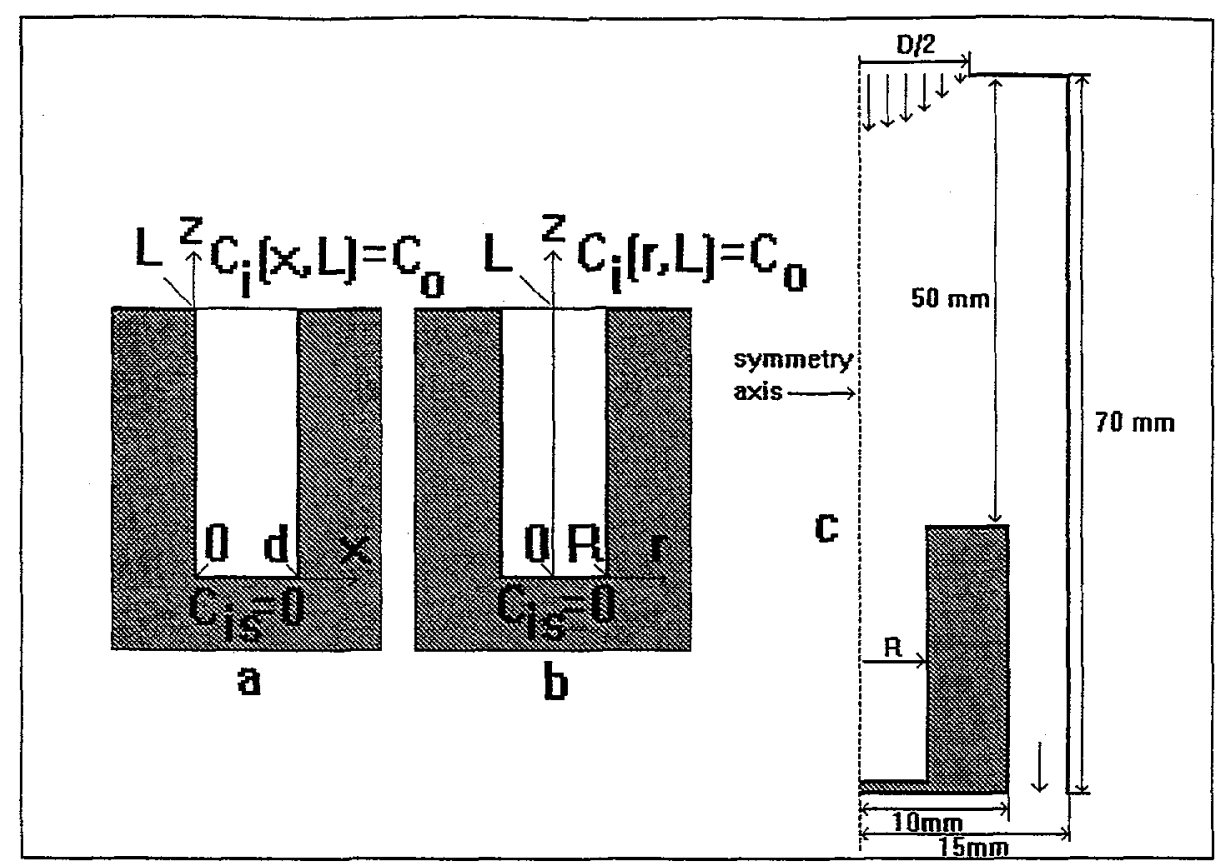

FIGURE 1. Geometry of cells: infinite rectangular split (a); cylindrical cell (b); stagnation flow reactor with cylindrical cell (c).
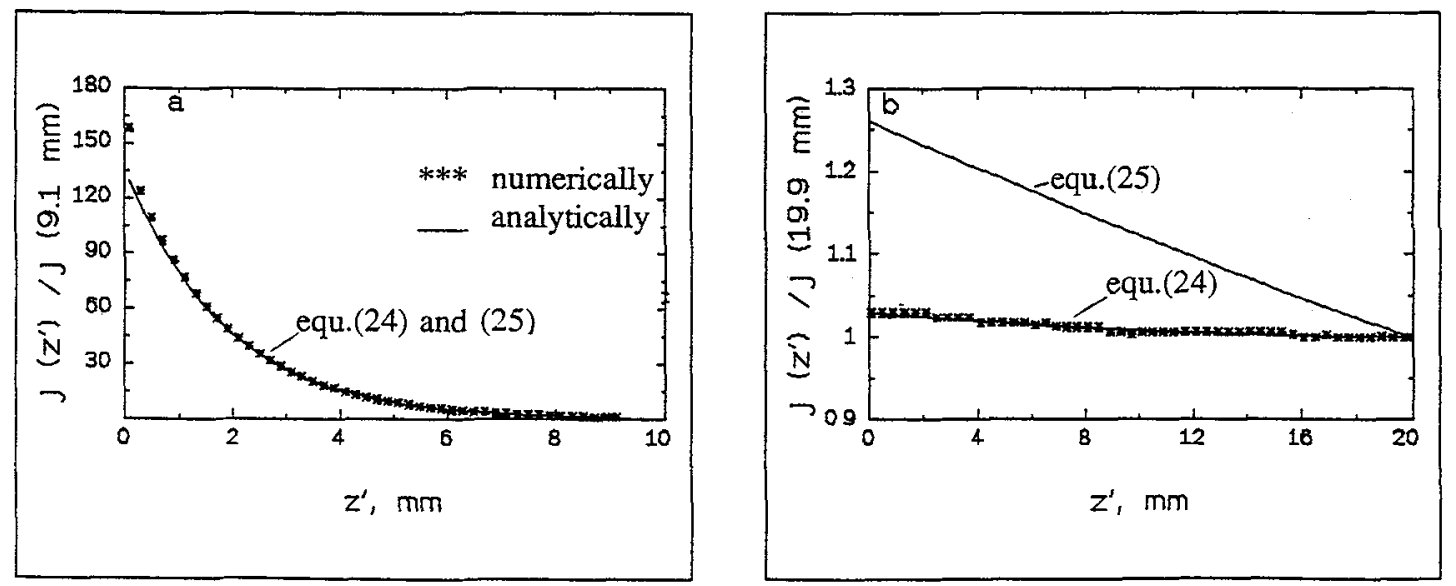

FIGURE 2. Simulation of deposition profiles of the component $\left(D_{i}=1 \mathrm{~cm}^{2} / \mathrm{s}\right)$ in the cylindrical cell ( $\mathrm{R}=2 \mathrm{~mm}, \mathrm{~L}=20 \mathrm{~mm}$ ) at $\mathrm{T}=1073 \mathrm{~K}$ for $\mathrm{Da}^{\mathrm{s}} 0.69$ (a) and $2.7 * 10^{-4}$ (b) (stagnation flow reactor, fig. $1 \mathrm{c}$ ). 

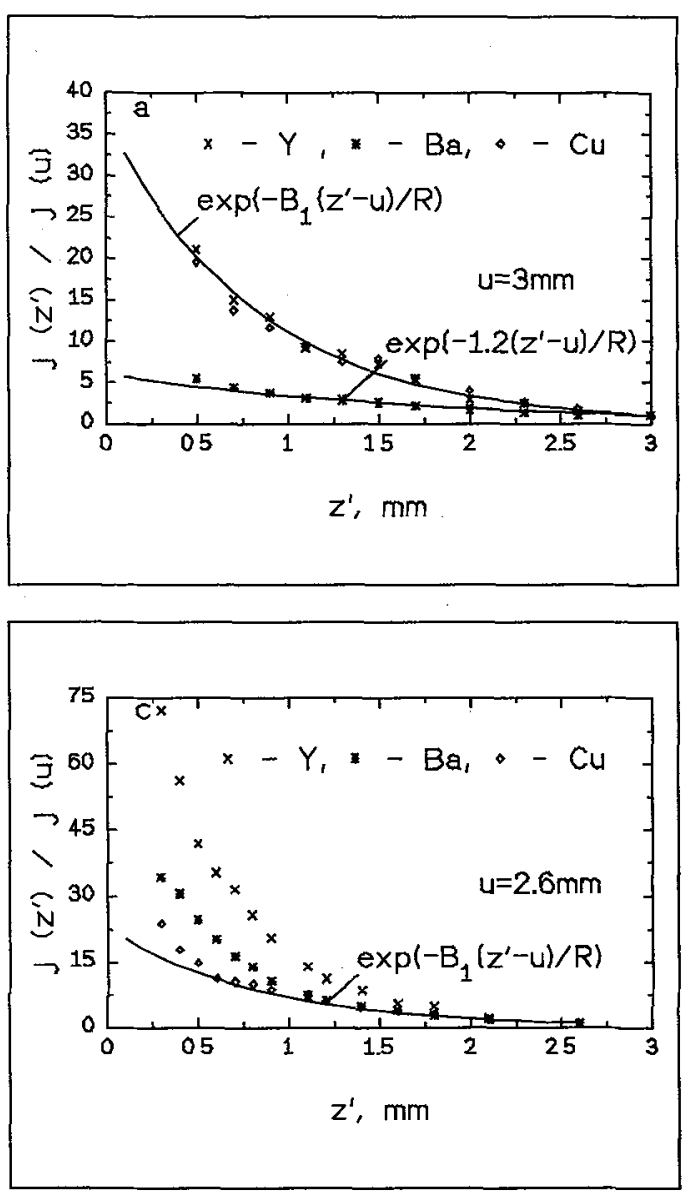

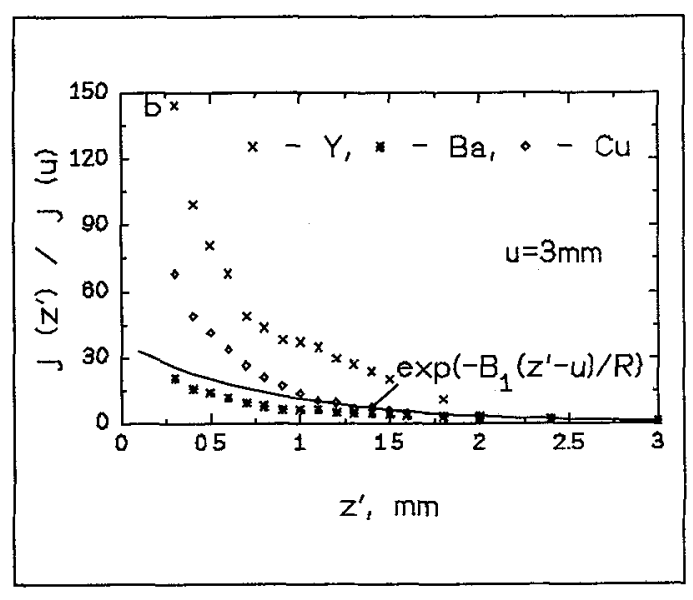

FIGURE 3. $j$ ( $z^{\prime}$ ) profiles for components of YBCO layers deposited by MOCVD in the cylindrical tube ( $2 \mathrm{~mm}$ radius, $20 \mathrm{~mm}$ length) at $650^{\circ} \mathrm{C}$ (a), $750^{\circ} \mathrm{C}$ (b) and $850^{\circ} \mathrm{C}$ (c) (stagnation flow reactor [16]). 